Comparison of the structure of sand-blasted and ground glass surfaces

This content has been downloaded from IOPscience. Please scroll down to see the full text. 1922 Trans. Opt. Soc. 2410

(http://iopscience.iop.org/1475-4878/24/1/303)

View the table of contents for this issue, or go to the journal homepage for more

Download details:

IP Address: 142.3.100.23

This content was downloaded on 08/09/2015 at 07:27

Please note that terms and conditions apply. 


\title{
COMPARISON OF THE STRUCTURE OF SAND- BLASTED AND GROUND GLASS SURFACES
}

\author{
By F. W. PRESTON, B.Sc., A.M.I.C.E. \\ (Issued from the Research Laboratory of Messrs Taylor, Taylor and Hobson, Ltd.)
}

MS. received I9th Fuly, 1922. Read and discussed, I2th October, 1922.

DR FrENCH, in a study of isotropic percussion figures (Nature, I2th Nov., 1919), came to the conclusion that "mere pounding of a glass plate cannot result in a smoothed surface of a technical order." I have already shown (Trans. Opt. Soc. $23(192 \mathrm{I}-22), \mathrm{I} 4 \mathrm{I})$ that the premises on which this conclusion was based are not valid, and that a smoothed or "grey" surface is produced by a process not markedly different from one of "pounding."

A more striking example of the similarity of ground and pounded surfaces is, however, illustrated in the accompanying photographs, in which a sand-blasted glass surface is compared step by step with ordinary abraded surfaces.

Fig. $x$ shows the commencement of a sand-blasting operation on a polished surface of glass. $\times 100$.

Fig. 2 shows a sand-blasting operation completed (the surface being now completely grey) and the specimen very lightly etched with hydrofluoric acid. Note the typical three-legged flaw near the centre of the field. $\times$ Ioo.

Fig. 3 shows a similar surface after more prolonged etching which develops the chatter grey flaws, which are characteristic of all abraded glass surfaces. $\times$ Ioo.

These three photographs may be compared one by one with Figs. 4 to 6, which show surfaces produced by lapping in the ordinary manner.

Fig. 4 shows the commencement of a "re-grey" with sharp carborundum on a polished glass surface. $\times 80$.

Fig. 5 shows a surface completely re-greyed with 15 minute emery and very slightly etched. $\times 33^{\circ}$.

Fig. 6 shows a surface completely ground with sand and etched to the state corresponding to that of Fig. 3. $\times$ roo.

The surfaces are so similar when produced by the two methods that they are practically indistinguishable either by the naked eye or the microscope, and the development of the structure by etching shows that the resemblance is not merely superficial but that the structure is in fact virtually identical.

Thus, contrary to Dr French's conclusions, it appears that mere pounding of a glass plate can, and does, produce a surface which is structurally indistinguishable from a smoothed surface of a technical order.

NoTE. The ground surfaces illustrated were produced by three different abrasives: the result would have been quite similar had the same abrasive been used throughout. Figs. 4 and 5 are the same as Figs. 17 and 20 in the paper on "The Structure of Abraded Glass Surfaces" (Trans. Opt. Soc.) referred to above. 


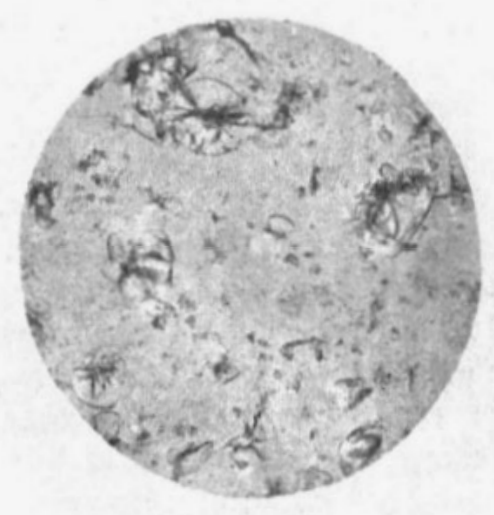

Ftg. 1 .

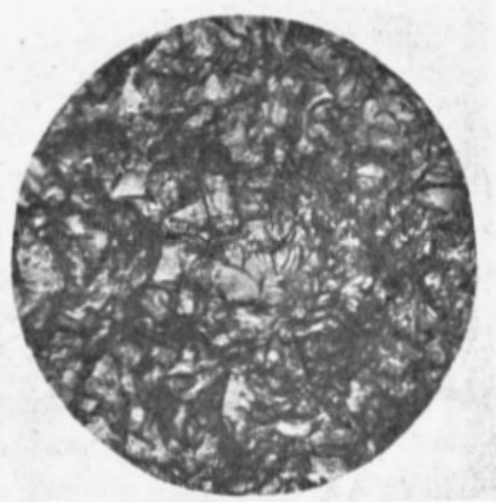

Fig. 2.

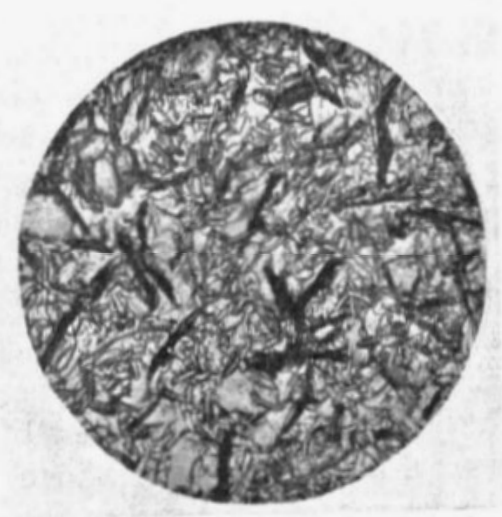

Fig. 3.

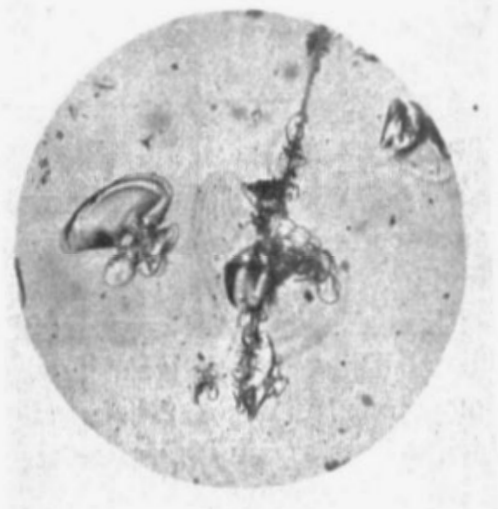

Fir. 4.

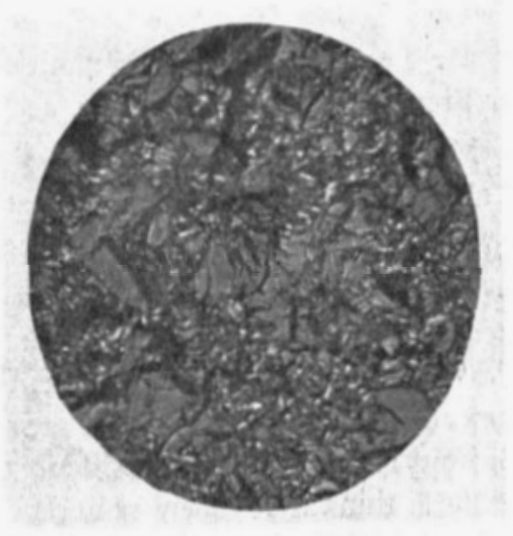

Fig. 5.

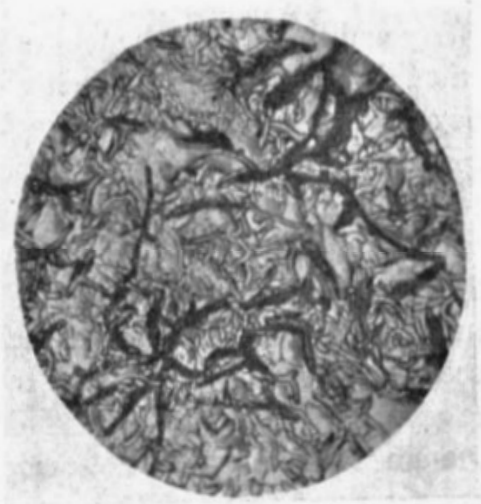

Fig. 6. 


\section{DISCUSSION}

. Mr P. F. Everitt: I do not see why any difference in appearance should be expected.

Mr F. Twyman: Without knowing the context I imagine that Dr French meant by a smoothed surface of a technical order one which is ready for polishing; there is nothing to indicate that one could obtain such a surface by sand-blasting.

I have examined the contours of ground glass and sand-blasted glass by means of a small machine designed for examining the contours of files. Although the photographs, of which I have only taken one in each case, exhibit no features which appear to me of importance in connection with the subject of this paper, yet I thought the method might be of interest in that connection, and the apparatus is exhibited to-night (see p. 48).

$\mathrm{Mr}$ J. Guild: Is there any method of designating the degree of coarseness of ground glass? It would be useful to have some standard scheme.

Mr Twyman: The only quantitative system I know of is the one suggested by Dr French (see Trans. Opt. Soc. I8 (I9I7), 21).

Mr Everitt: The standard works method is to designate the surface by the kind of abrasive used. The degree of coarseness obtained with a given abrasive varies, however, with the length of time, the material, and the worker.

Dr J. W. French (communicated): I was unable to take part, as I should have liked, in the discussion of Mr Preston's earlier paper on “The Structure of Abraded Glass Surfaces "-a subject in which I am particularly interested-and I welcome his more recent paper devoted to a statement made by me in Nature as it affords an opportunity of dealing with the evidence upon which he bases his theory and opposition.

I still think that "mere pounding of a glass plate cannot result in a smoothed surface of a technical order." The word "technical" suggests a search for ocular proof in the smoothing shop. What do we see there? When commencing the process the operator carefully lowers the metal smoothing tool upon the glass surface and the heavier the tool or the more drastic the abrasion, the gentler is his action. With equal care he gently lowers the driving arm pin into the tool socket. His anxiety is to avoid a pounding action that would occasion severe local vertical pressures at points over the surface. Having successfully avoided the danger of pounding action and having reached the translation stage in which I consider the essence of successful abrasion lies, his attitude of almost anxious carefulness relaxes. There being no longer danger of mere vertical pounding action, he cheerfully starts up the machine, causes the tool to move rapidly over the work, and, if necessary, increases the pressure to the desired extent. I have great confidence in the experienced craftsman and I do not think those in charge would be justified in issuing instructions to the smoothing operators that care in applying the tool is unnecessary and that the driving pin may be banged into the socket because pounding does not matter. 
Mr Preston evidently regards a sand-blasted surface as a pounded one and definitely states that such a surface is indistinguishable from a ground one. Specimens of both types are illustrated in support of these views. But frankly I am astonished that such specimens should be illustrated as technically smoothed ones of the type referred to in my statement. Even making no allowance for the partial etching, I regard them as being at least five times as coarse as a decently smoothed surface. It is generally recognized that the greatest care in smoothing receives ample justification in the subsequent polishing operation. It is true Mr Preston uses the words "re-grey" and "ground," but if he does not regard the surfaces illustrated as technically smoothed, it is difficult to understand why rough-ground surfaces should be used to refute a statement concerning smoothed surfaces.

If I understand Mr Preston's position, his arguments are:

(I) that pounding is the essence of sand-blasting action;

(2) that a sand-blasted surface is indistinguishable from a smoothed one.

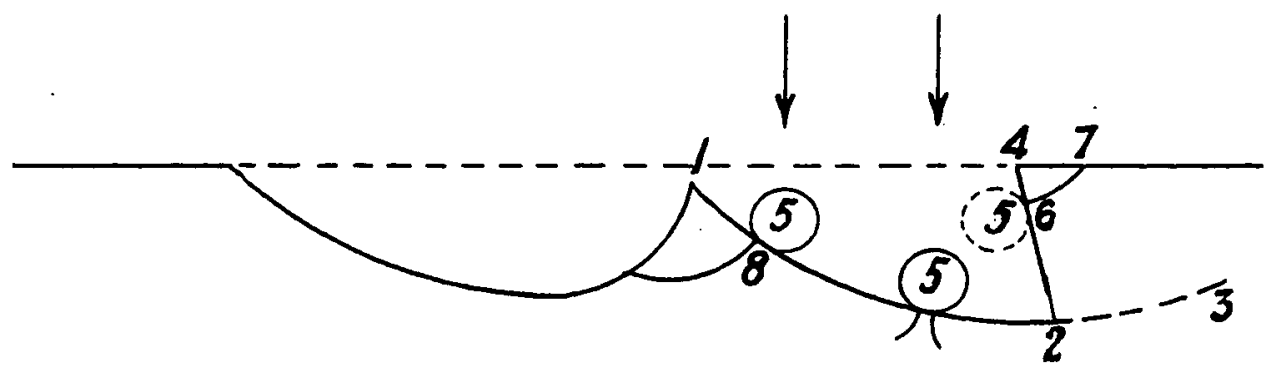

Fig. A

With argument No. (2) I have already dealt. What about No. (1)? That the action is a complex one hardly needs emphasis. It involves more than the simple pounding that $\mathrm{Mr}$ Preston suggests. Let us consider a surface, Fig. A, that has been broken up by whatever means preparatory to smoothing, and let us assume that the sand grains are projected normal to the surface, a condition not altogether easy of attainment. In the illustration the fractures $1,2,3$ and 4,2 have intersected at 2 and the portion $1,2,4$ has been removed. The face 4,2 is shown overhanging because, although the section is presented as an assumption, it is really typical of one that may often be observed if two worked surfaces are pressed tightly into optical contact and if, after the face normal to the section has been ground, the parts are separated for examination of the contour. Suppose the grain of sand 5 impinges on the base of the depression: there is certainly danger there of a cone fracture, the result of mere pounding; but it is probable that the fracture 2,3 will be extended in the direction indicated by a dotted line. If the sand grain 5 rebounds and strikes the face 4,2 it is still more probable that 2,3 will be extended towards the free surface, not downwards, and a splinter $4,6,7$ may also be produced. Thus, with such pounding as may occur, there is probably associated a more important abrasive action as I understand it. Generally, however, a grain will strike obliquely, 
as indicated at 8 . 'The force of impact will be exerted, not vertically in the direction of the sand-blast, but normally to the surface and the conditions are then exactly those of the experiment which I described in Nature.

Particular importance appears to be attached to Fig. 26 of the earlier contribution, illustrative of a surface crack. It may be a crack, but more probably it is not. The appearance is a very familiar one, most frequently attributable to deviation of transmitted light by an overhanging face, such as 4,2 of my Fig. A illustrated above, and the consequent absence of the corresponding light from the field of view of the microscope. True fissures rarely open sufficiently to permit of their heing detected in this way: other methods are necessary. Thus, for example, the surface illustrated by the photomicrograph, Fig. B (magnification $4^{\circ}$ diameters) appeared perfect before treatment. According to Mr Preston, it might comprise a million minute fissures per square inch. Fortunately it is quite easy to test such

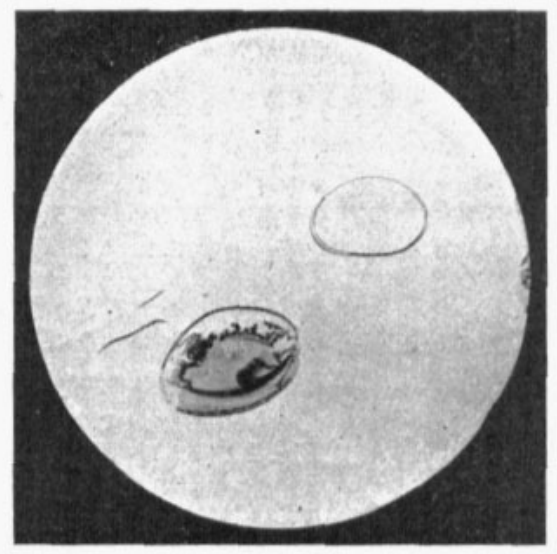

Fïg. B

an assertion. The hard crown specimen in question was boiled in water for twenty minutes and its defects brought into view as the result of thermal expansion, and the solution first of alkali and later of silica. In neither of the main faws has the splinter actually been detached, although the water has penetrated extensively under one of them. Two lines that indicate the outcrop of otherwise invisible fissures are also evident. But these defects are accidentals. No other kindred flaws can be distinguished under the most critical microscopic examination. Had "a million fissures per square inch" existed many of them would have been exposed by the method described. The defects illustrated are attributable, in an earlier stage, to pounding. In other respects the specimen is a remarkable one, but to raise new issues in a discussion is not permissible and I must refrain from dealing with them.

In his earlier paper Mr Preston claims to have proved definitely his flaw-complex theory and his chief argument seems to be based upon the remarkable appearance of strain at a ground surface, to which attention was first directed by Mr 'Twyman. 


\section{Comparison of Structure of Sand-blasted and Ground Glass Surfaces}

To justify the theory for which there is presented no other definite evidence, $\mathrm{Mr}$ Preston suggests that in the process of abrasion there is formed a multitude of fissures into which are jammed small fragments that compress the substance, thus giving rise to the appearance of strain when viewed by polarised light.

My experiment described in Nature clearly indicated that a true percussion fracture does not originate at the point of impact but around it, quite out of contact with the grain. A considerable stretch of the imagination is thus required to imagine that these percussion fractures stretch sufficiently to become jammed open, without assistance, by fragments that may casually fall into them.

The Nature experiment also described the formation of fractures immediately under the point of the grain when the impact was sufficiently severe and it is quite conceivable that fragments could in such a case be jammed into the fissures. But when glass collapses under such circumstances the area affected is quite visible under the microscope and the presence of such defects could be no question of mere hypothesis.

I cannot understand Mr Preston's difficulty in viewing the contours of smoothed glass surfaces. Personally I have spent many pleasant hours exploring them and I have never detected defects of the type referred to that were not of a casual and accidental kind.

Mr Preston's explanation of the Twyman effect is, I think, quite untenable. To provide an alternative one that can be substantiated by definite proofs is not easy. Most of the experiments I have made can be interpreted in different ways. My explanation of the phenomenon is as follows: The structureless surface of glass is subjected to tension forces much more intense than is generally realised. This statement is applicable to the structureless surface layer of the irregularities of a ground surface. At a ridge the adjacent surfaces are more or less inclined to the general horizontal of the ground surface and the tension forces of the inclined surfaces exercise forces normal to the general horizontal. Whereas the tension force of a flat worked surface is tangential, a ground surface is subjected to a multitude of vertical forces. Now if a flat worked surface is subjected to numerous distributed forces not sufficiently intense to cause percussion flaws, the Twyman effect can be produced. The coarser the grinding, the higher are the ridges likely to be, and the greater the normal forces and the appearance of strain. Very slight etching or polishing removes the peaks of the ridges where the faces are most normal and, in consequence, the appearance of strain is greatly reduced. This is all in accordance with experimental results.

I have dealt at considerable length with Mr Preston's arguments, not from any particular desire to substantiate a personal statement that has been challenged, but frankly because I regard Mr Preston's theory as having but little foundation in fact and as being particularly dangerous in its workshop application.

Mr Preston (communicated): I wish to thank the members of the Society for their contributions to the discussion and am glad to find that the properties of abraded surfaces are a subject of general interest.

While I agree with Mr Everitt that on calm reflection there is no logical reason 
why we should expect any fundamental difference in a sand-blasted and a ground surface, nevertheless the two processes appear superficially so different that I would myself have hesitated to express that opinion without experimental confirmation. That the matter is not altogether self-evident is clear from the difficulty Dr French has in accepting it. By a ground surface I mean one produced by a tangential movement of the abrasive. By a smoothed* surface is ordinarily meant a finely ground one: there is no objection, for the present purpose, in accepting Dr French's definition, that a smoothed surface is one ground as finely as possible.

In accordance with Dr French's article in Nature, we define a pounding action as the exertion of a sensibly normal pressure or impact between abrasive and glass: and with him we agree that a pounded surface is to be recognised by the presence of penetrating flaws as a characteristic feature. In the article in Nature Dr French argues that the tangential movement of grinding must produce, by reason of the obliquity of the thrust, a very different structure from a pounding action, when the thrust is sensibly normal. He is led to this argument by the assumption that penetrating flaws are absent from a smoothed surface. The purpose of my earlier paper was to show that such flaws are by no means absent: that they play a very important part in the structure of ground (and smoothed) surfaces.

The purpose of the present paper is to record that, as might be expected, similar flaws are present in sand-blasted surfaces; and further, that the structure of ground surfaces is essentially a pounded structure, scarcely distinguishable from a sand-blasted one. I say that sand-blasting is a pounding action, because it produces penetrating flaws, which is Dr French's own criterion. Dr French now argues at some length that it is not simple pounding, that there is a good chance of many of the new fractures breaking out at the free surface: but he finishes by saying that "generally the conditions are exactly those of the experiment I described in Nature"-i.e. generally we shall get penetrating flaws and a pounding action. It being agreed, then, that a sand-blasted surface is for our purpose a pounded surface and full of penetrating flaws, the point at issue is simply whether a ground surface is similar or not. Mr Everitt's deductions from first principles are here unimpeachable. A ground surface is a pounded surface because the obliquity of the thrust is small: in fact the thrust is sensibly normal, the coefficient of friction between tool and glass being quite low $\dagger$. If the conditions of Dr French's drawings in Nature held good, the coefficient of friction would be very high, and it would require far more effort to slide the glass over the tool than to lift it bodily away. Anyone who has worked glass by hand knows this is not so.

" Many shops, especially in America, do not use this term: a surface is spoken of as "fined" or "fine-ground."

$t$ I hope to deal with this and allied phenomena in detail in a future communication. It must be noted here, however, that the friction appears to rise in the later stages as the emery is worked down very fine. This is a capillary phenomenon, the surface tension of the water adding greatly to the normal thrust, and therefore increasing the tangential drag, but the coefficient of friction remains small. We might possibly reconcile a low coefficient of friction with Dr French's views if we supposed that a majority of the grains carried a heavy normal load without fracturing the glass, while a minority carried a heavy tangential thrust and were the active abrading particles. This explanation is seen to be inadequate in view of what follows. 
But let us not rely too much on theories, for that seems to be the chief source of Dr French's troubles. The proof that a smoothed surface contains flaws is best obtained by examination of the surface itself. Dr French complains that boiling water does not etch out the flaws: he would save time by using hydrofluoric acid. His specimen was boiled for twenty minutes, and he speaks of the "solution first of alkali and later of silica." He does not state how much alkali and silica were actually dissolved, but I venture to think that no ordinary balance would have detected it.

By the courtesy of Messrs H. R. Moulton and C. H. Ohlweiler, of the American Optical Company, I am able to record the following experiment. A thin piece of hard spectacle crown glass was carefully smoothed on both sides by hand. It was then cut into two pieces, each of approximately $20 \mathrm{sq} . \mathrm{cm}$. of smoothed surface. One piece was etched in hydrofluoric acid till the flaws showed as well defined sausage-shaped marks. The loss of weight was 0200 gramme. This corresponds to a condition of etching a trifle short of the stage illustrated in Fig. 6 (but beginning of course with a fine grey). The other piece was now boiled in distilled water for approximately 48 hours. The loss of weight was $\cdot 0038$ gramme, about one-fifth of that due to a few seconds etching with dilute hydrofluoric acid. The flaw structure was however distinct, corresponding roughly to the stage illustrated in Fig. 5 . Thus all that Dr French need do, if he wishes to develop the flaws with plain water, is to boil long enough*.

Dr French has objected that none of my surfaces are particularly finely ground: the objection would be valid if he believed that a very finely-ground surface were radically different from a moderately fine ground one. But his argument hitherto has been that it is the tangential motion, not the size of the abrasive, that makes a smoothed surface different from a pounded one. I can however state that the size of abrasive has nothing to do with it: a well smoothed surface worked with 60 minute emery is as full of flaws as a 20 minute emery smooth: the flaws are not so big, but there are more of them. Not many people would suppose that a well worked I $_{5}$ or 20 minute emery smooth differed in nature from a very finely-ground surface, except in the matter of size, but those who think it possible may easily reassure themselves with the aid of a microscope and a little hydrofluoric acid. It will be found in every case that a ground surface-coarse or smooth-is a flaw complex, a pounded structure.

I think that one of Dr French's main difficulties arises from his drawings: he has deduced what ought to happen from false premises. Both in his present Fig. A and in his article in Nature he draws his abrasive very small in comparison with the existing irregularities and shows them producing new fractures much smaller than the existing ones. The surface would, under these conditions, pass almost instantly from a very coarse structure to a very fine one. Now in sandblasting the structure does not get any finer with continued blasting, and in smoothing it only gets finer by very slow stages. The new fractures must be drawn

* A trace of acid (such as sulphuric) will greatly reduce the rate of etching. A little alkali will no doubt increase it.

Optical xxrv 
as large as the old ones. Further, from such observation as I have made, I believe that the abrasive should be at least two or three times as large as the largest irregularities of the surface it produces*: generally it should be larger still. Consequently Fig. A should be replaced by a design something like Fig. 7 , the dotted lines showing possible new fractures. When an angular abrasive is used in place of the smooth spheres, a greater variety of fractures is possible. Some of these will probably re-intersect the free surface, but many will be penetrating flaws extending below it.

Dr French emphasises the care which workmen exercise in placing tool and glass together, and suggests that no care is exercised in starting up the translatory motion. The practice of different shops possibly varies a little in this respect, but where a really fine smooth is needed, even greater care is exercised in starting the

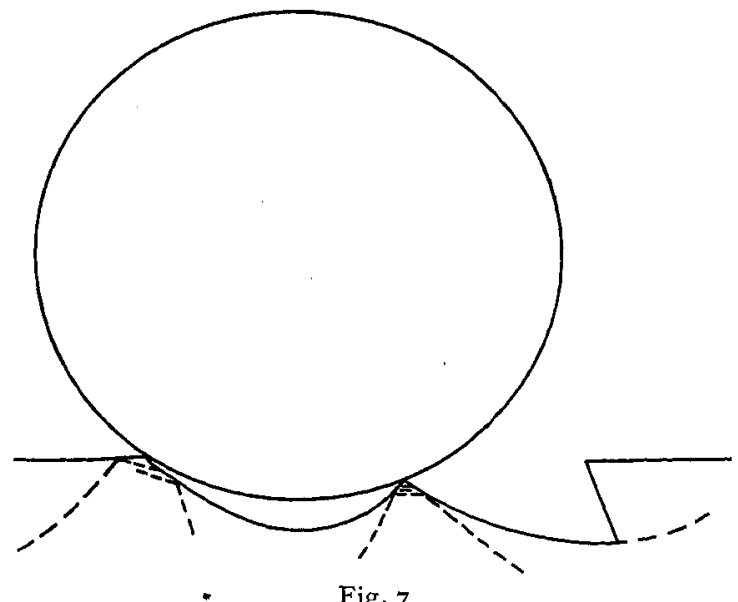

rotation than is used in placing tool and glass together. Thus in working a piece of glass by hand, we feel our way gently all over the tool, not starting the rotation till the glass has passed once over every part of it. Similarly in working a machine, before we lower the pin, we give the block a few slow passes over the tool by hand: then we may start the machine up without hesitation. If we do not we are liable to get "cuts" (grinding scratches), due to some coarse particle trapped between glass and tool. After a few revolutions of the smoothing operation, when any large grains have been pushed away or broken down, the pin may be lifted and allowed to fall with relative violence: we may even strike the tool with a hammer or a lump of iron, and we shall not damage the surface of the glass. This in fact is sometimes done if tool and glass stick very tightly in the later stages by capillary attraction. It is not recommended however that violence of any sort be used in

* My measurements relate to coarse and fine smoothing emeries, the emery being examined after use. Fractures produced by impact of smooth steel balls are, in general, much smaller still. 
an optical glass workshop, for though it is not likely to harm the surface of the glass it will possibly fracture the pitch or plaster that supports it. Thus what we are afraid of is not a vertical load, but a localised load, especially a load on a coarse piece of grit. We are very much afraid of such coarse particles, and we are even more afraid of their powers for evil under a translatory motion than we are under a vertical (normal) impact.

The second part of Dr French's comments is concerned more particularly with my earlier paper. The flaw shown in Fig. 26 of that paper is sworn to as genuine by Sir Herbert Jackson, who kindly provided the photograph. I probably never saw this particular object myself, but I did see at his laboratories many similar objects, and there were many hundred thousands of them to the square inch. All who saw them were satisfied that they were flaws: that they were shadows of a surface feature seems scarcely likely, as the surface was oiled down in homogeneous immersion. Dr French managed to develop two somewhat similar objects in his specimen of Fig. B: these he has no difficulty in accepting as "otherwise invisible fissures": why then object to Sir Herbert Jackson's photograph?

We now come to the Twyman effect. I agree that in percussion flaws made by smooth round balls on a polished surface of glass, the fracture "cone" originates quite outside the area of contact: this indeed was pointed out many years ago by Auerbach and others. In such fractures there is sometimes little permanent strain produced, but there is nearly always some. With more irregular abrasives the flaw becomes more irregular and the permanent strain greater. With a given abrasive the permanent strain is greater, the more violent the impact: it all depends on how much matter can enter the fissure. With a keeled or angular abrasive the penetrating flaws often originate in the area of contact and matter is easily forced into the fissures. In my earlier paper I showed that a glazier's diamond leaves a threefold flaw, and that the lateral ones (at least) open sufficiently to show a number of interference bands. I also illustrated the commencement of a re-grey, where the cone-fissures (resembling, in this distorted form, a butterfly's wing) show interference bands in the same way (Fig. I 7 of earlier paper). Professor Raman, in his note in Nature, which was the primary cause of Dr French's contribution to the same journal, illustrates a typical fracture from a round ball and calls attention to the fact that the flaw has opened, showing a number of interference bands. It is futile to argue from preconceived notions that the flaw will not open sufficiently to let in foreign matter, when the specimens themselves show, not only that the fractures open at the moment of their formation, but that they stay open afterwards.

Observation of the process of flaw making with steel balls shows, moreover, that the flaw opens much further while the load is on the ball, and that the flaw partially closes on the removal of the load. Anything that may get into the fissure will therefore be apt to be trapped in it. Since I have been in America I have been fortunate enough to find examples of percussion flaws into which rouge had penetrated quite a distance, though presumably after the time of formation. The specimens were from the routine production of a large plate glass plant. We have 
here ocular proof of foreign matter getting into percussion flaws, but I think that usually the only foreign matter is very fine glass debris from the lips of the fracture itself, and that it enters at the moment of formation.

Dr French ventures, very tentatively, an alternative explanation of the Twyman effect, which is however quite inadmissible. The "appearance of strain" is no mirage: Mr Dalladay (Trans. Opt. Soc. 23 (192I-2), 170) has shown that this strain has a very definite distribution, a distribution that can only be accounted for by the presence of a tangential thrust in the grey surface-a surface compression. The invocation of the normal component of a supposed "tension force" in the. surface does not explain anything and violates the laws of mechanics. For, to prevent the specimen moving off bodily into space, the downward pull from a ridge must be balanced by the upward pull from a valley: and this is true even if the ridge be sharp and the valley a smooth trough. The normal component of any surface force must be equilibrated within a depth scarcely greater than the thickness of the grey layer: it will produce no "appearance of strain" at all beyond this point-still less will it produce a Twyman effect, where the distribution of stress is such as has been described by Mr Dalladay. This objection alone is fatal, but many others equally so could be given: but the tentative manner in which $\mathrm{Dr}$ French puts the matter forward suggests that he is aware of its imperfections. It is therefore not necessary to enlarge on the subject.

I am interested to hear $\mathrm{Mr}$ Twyman state that there is a difference in the contours of smoothed and sand-blasted surfaces: but I cannot agree that the ground surface is finer than the other, if the same abrasive is used in both cases. I imagine Mr Twyman means that in smoothing we use a finer abrasive than in sand-blasting and obtain a much finer surface. But when the same abrasive is used, we see from Figs. 3 and 6 that the structure is alike, not only in outline, but in scale.

Mr Guild raises the question of some satisfactory means for designating the quality of a smoothed surface. This is a recognised need of the workshops in every glass working industry at the present time. The trouble is that the quality of the ultimate polished surface depends chiefly on the presence or absence of a few odd "holes" or flaw-centres coarser than the general texture of the smooth. It is better to have a moderately fine surface of an even texture than a very fine surface with a few very coarse fractures. All the scientific methods proposed to date give only an opinion of the average texture. Visual inspection is the only useful guide we have at present, and even that is apt to be deceptive.

In conclusion I would attempt to visualise the process of smoothing, or grinding, as best we can at the present time. It appears that the irregular grains of abrasive are dragged or rolled about by the tool and every now and then a grain is crushed against the glass. Then the glass or abrasive (or both) is fractured. If the abrasive is fractured it breaks down into smaller grains. If the glass fractures, there are usually found irregular flaws penetrating beneath the surface. The intermittent crushing together of grain and glass is a true pounding action and the resulting glass surface is a typical "pounded" surface. The flaws are mostly "percussion" 
flaws-crushing flaws, of a rather irregular type (as befits the irregularity of the abrasive): they are not, as a rule, chatter flaws. In my earlier paper I tentatively described these flaws, when etched out on a partially polished surface, as "chatter grey," without implying however that this was produced by a true chattering action. In future I propose to use the term "percussion grey" and to reserve the term "chatter flaws" for the true chatter sleeks. True chatter sleeks are occasionally found in grinding, but they are much more characteristic of the polishing operation. The flaws of a ground (smoothed) surface are not commonly associated into sleeks or scratches: they often centre around percussion spots, and arise not from a chattering, but from an intermittent pounding action. 